\title{
Bimetallic oxide coupled with B-doped graphene as highly efficient electrocatalyst for oxygen evolution reaction
}

\author{
Yuanyuan Jiang ${ }^{1}$, Kai Dong ${ }^{1}$, Yizhong Lu ${ }^{1 *}$, Jiawei Liu ${ }^{2}$, Bo Chen ${ }^{2 *}$, Zhongqian Song ${ }^{3}$ and Li Niu ${ }^{3}$
}

\begin{abstract}
Developing electrocatalysts with high performance and low cost for the oxygen evolution reaction (OER) is of great importance for fabricating renewable energy storage and conversion devices. Here, a series of boron-doped graphene (BG)-supported bimetallic oxides of $\mathrm{Co}$ and $\mathrm{Ni}$ were obtained and served as OER electrocatalysts. Surprisingly, the annealed $\mathrm{Co}-\mathrm{Ni}-\mathrm{O}_{x} / \mathrm{BG}$ with a $\mathrm{Co} / \mathrm{Ni}$ ratio of $1: 1$ exhibits high performance toward oxygen evolution in alkaline electrolyte. The overpotential is only $310 \mathrm{mV}$ at the current density of $10 \mathrm{~mA} \mathrm{~cm}{ }^{-2}$, superior to many mono-metallic oxides reported before, and even comparable to the commercial $\mathrm{RuO}_{2}$. The regulation of charge distribution in bimetallic oxides and the strong synergistic coupling effects together contribute to the superior electrocatalytic performance of the $\mathrm{Co}-\mathrm{Ni}-\mathrm{O}_{x} / \mathrm{BG}$ toward OER. This study also offers several effective ways to design high-performance OER electrocatalysts for water splitting.
\end{abstract}

Keywords: bimetal oxide, B-doped graphene, oxygen evolution reaction, electrocatalyst, hydrogen generation

\section{INTRODUCTION}

With the ever-growing focus of attention on the global energy shortage and environmental pollution, exploring clean and renewable energy source is unprecedented during the last few decades $[1,2]$. Among these innovative solutions, the production and storage of hydrogen $\left(\mathrm{H}_{2}\right)$ is appealing for its high mass-specific energy density and the clean nature $[3,4]$. Some methods are frequently used for generating hydrogen, such as reforming fossil fuels and electrolysis of water. Considering the factors including cost, purity and the environmental implication, the most promising way to produce $\mathrm{H}_{2}$ is water splitting triggered by sunlight or electricity [5]. However, the anodic oxygen evolution reaction (OER) during water splitting always suffers from sluggish kinetics process with complicated multi-electron transfer steps, leading to undesired large overpotential [6]. Therefore, exploiting OER catalysts with high activity and stability is vital to increase the overall efficiency of the water splitting. Some noble metal-based compounds, such as iridium oxide $\left(\mathrm{IrO}_{2}\right)$ and ruthenium oxide $\left(\mathrm{RuO}_{2}\right)$, have been regarded as the state-of-the-art OER electrocatalysts for their low overpotentials and Tafel slopes [7-9]. Nevertheless, the scarcity, high cost and unacceptable durability of these noble metal-based electrocatalysts hinder their commercial implementation $[10,11]$. Thus it is highly imperative to develop earth-abundant element-based catalysts with decent activity as well as long-term stability for the oxygen evolution process [12].

Hitherto, transition metal catalysts, especially cobaltand nickel-based electrocatalysts, have drawn tremendous attention because of their attractive features, such as availability, low cost and superior activity [13]. Over the past years, transition metal oxides/hydroxides [14-16], sulphides $[17,18]$, phosphides $[19,20]$, and borides $[21,22]$ have been extensively investigated as OER electrocatalysts. Although the sulphides, phosphides and borides have shown better catalytic activity than the oxides in some cases, they suffer from lower controllability, more harsh condition, and probable contamination during the syntheses. Among these well-developed catalysts, the transition metal oxides (especially cobalt/nickel oxides) have attracted increasing attention on account of their unique $3 \mathrm{~d}$ electronic configurations and high stability. Nevertheless, the oxides generally exhibit low OER elec-

\footnotetext{
${ }^{1}$ School of Materials Science and Engineering, University of Jinan, Jinan 250022, China

${ }^{2}$ Center for Programmable Materials, School of Materials Science and Engineering, Nanyang Technological University, Singapore 639798, Singapore

${ }^{3}$ Center for Advanced Analytical Science, c/o School of Chemistry and Chemical Engineering, Guangzhou University, Guangzhou 510006, China

*Corresponding authors (emails: mse_luyz@ujn.edu.cn (Lu Y); bchen005@e.ntu.edu.sg (Chen B))
} 
trocatalytic activity due to their inferior intrinsic electrical conductivity and inevitable self-aggregation. Therefore, developing a facile way to modulate the electrical conductivity and the charge distribution of the metal oxides is necessary to improve their electrocatalytic activities. Coupling the metal oxides with highly conductive carbon nanomaterials, including but not limited to carbon nanotubes and graphene, has been testified to be an effective way to facilitate the charge transport and increase the exposure of active sites [23,24]. Furthermore, incorporating a second metal into the metal oxide catalysts has been proposed as an efficient strategy to modulate the charge distribution and energy level, due to their synergistic effects $[25,26]$. For example, it has been reported that multi-metallic electrocatalysts such as $\mathrm{Co}-\mathrm{Ni}-\mathrm{B}-\mathrm{O}$ nanosheets [27], $\mathrm{CoNiP}_{x}$ [28], CoMoS [29], CoMoB [30] and $\mathrm{CoFe}$ layered double hydroxides [31] exhibit distinctly improved catalytic activity for the OER process, compared with their mono-metallic counterparts.

Herein, we report a room-temperature chemical reduction method combined with a subsequent annealing treatment to fabricate a bimetallic oxide strongly coupled with two dimensional (2D) boron-doped graphene sheets (Co-Ni-O $\left.\mathrm{O}_{x} / \mathrm{BG}\right)$. Benefiting from the highly exposed surface active sites, enhanced electron transfer capacity and strong synergetic coupling effects, the as-prepared $\mathrm{Co}-\mathrm{Ni}$ $\mathrm{O}_{x} / \mathrm{BG}$ hybrid exhibits a high activity for OER with an overpotential of $310 \mathrm{mV}$ at the current density of $10 \mathrm{~mA} \mathrm{~cm}^{-2}$ and a Tafel slope around $54.8 \mathrm{mV} \mathrm{dec}^{-1}$ in alkaline electrolyte, which is among the best, compared with the transition metal oxide-based OER electrocatalysts reported. Therefore, this study proposes a facile and effective way to improve the OER electrocatalytic activity of the transition metal oxides which have intrinsic lower electron transfer kinetics than their counterparts, such as phosphides, sulfides, etc. The strategies proposed in this study are not only appropriate for improving the electrocatalytic performance of metal oxides, but also valuable for designing highly-active transition metalmetalloid-based electrocatalysts.

\section{EXPERIMENTAL SECTION}

\section{Chemicals}

$\mathrm{Co}\left(\mathrm{NO}_{3}\right)_{2} \cdot 6 \mathrm{H}_{2} \mathrm{O}, \mathrm{NaBH}_{4}, \mathrm{Ni}\left(\mathrm{NO}_{3}\right)_{2} \cdot 6 \mathrm{H}_{2} \mathrm{O}$, Nafion solution (5 wt.\%) and $\mathrm{RuO}_{2}$ were obtained from Sigma-Aldrich; $\mathrm{KOH}$ was obtained from Beijing Chemical Corporation; aqueous solution of graphene oxide (GO) $\left(2.0 \mathrm{mg} \mathrm{mL}^{-1}\right.$ single layer $\mathrm{GO}$, with the size in the range of $0.5-5 \mu \mathrm{m}$, and the thickness of $0.8-1.2 \mathrm{~nm}$ ) was ac- quired from XFNANO Corporation. All reagents were analytical grade and used without any further purification.

\section{Synthesis of $\mathrm{Co}-\mathrm{Ni}-\mathrm{O}_{x} / \mathrm{BG}$ and the samples in the control experiments}

The $\mathrm{Co}-\mathrm{Ni}-\mathrm{O}_{x} / \mathrm{BG}$ was prepared with a room temperature chemical synthesis method, followed by annealing treatment. In a typical synthesis, $0.5 \mathrm{mmol}$ of cobalt (II) nitrate hexahydrate $\left(\mathrm{Co}\left(\mathrm{NO}_{3}\right)_{2} \cdot 6 \mathrm{H}_{2} \mathrm{O}\right)$ and $0.5 \mathrm{mmol}$ of nickel (II) nitrate hexahydrate $\left(\mathrm{Ni}\left(\mathrm{NO}_{3}\right)_{2} \cdot 6 \mathrm{H}_{2} \mathrm{O}\right)$ were added into $100 \mathrm{~mL}$ of deionized water under continuous and vigorous stirring to complete dissolution. Then, $7.5 \mathrm{~mL}$ of $\mathrm{GO}\left(2.0 \mathrm{mg} \mathrm{mL}^{-1}\right)$ aqueous dispersion was added to the above solution and stirred for another $30 \mathrm{~min}$. After full electrostatic attraction of the $\mathrm{Co}^{2+}$ and $\mathrm{Ni}^{2+}$ on the GO nanosheets, $5 \mathrm{~mL}$ of sodium borohydride $\left(\mathrm{NaBH}_{4}, 0.5 \mathrm{~mol} \mathrm{~L}^{-1}\right.$, prepared at $0^{\circ} \mathrm{C}$ and deaerated with Ar gas) solution was slowly dropped in and maintained at room-temperature for $40 \mathrm{~min}$ under vigorous stirring. The resulting products were gathered by centrifuging and washed with ethanol and water, successively. The asprepared precursors were dried by lyophilization. The graphene-supported bimetal oxides with other Co:Ni ratios were also synthesized by varying the molar ratio of the metal precursors $(2: 1,1: 2)$ with the same total amount of the transition metal $(1 \mathrm{mmol})$ under the same condition. Mono-metallic oxides were also prepared for comparison, in which only Co salt or Ni salt was used with a quantity of $1 \mathrm{mmol}$ to prepare cobalt oxide and nickel oxide, respectively. The annealed $\mathrm{Co}-\mathrm{Ni}-\mathrm{O}_{x} / \mathrm{BG}$ was synthesized by annealing the precursor powder under Ar at $400^{\circ} \mathrm{C}$ for $2 \mathrm{~h}$. The samples were also annealed at other temperatures $\left(300,500,600^{\circ} \mathrm{C}\right)$ for comparison.

The graphene sample and the unsupported $\mathrm{Co}-\mathrm{Ni}-\mathrm{O}_{x}$ sample in the control experiments were synthesized with the same procedure, without adding the transition metal salts and GO, respectively.

\section{Electrochemical measurements}

We investigated the electrochemical performances of the electrocatalysts on a CHI 760E electrochemical workstation. The electrocatalyst inks were obtained by dissolving $4 \mathrm{mg}$ of catalyst powder in a mixed solution composed of $0.4 \mathrm{~mL}$ of water, $1.56 \mathrm{~mL}$ of isopropanol, and $40 \mu \mathrm{L}$ of Nafion ( $5 \mathrm{wt} . \%$ ) to form a $2 \mathrm{mg} \mathrm{mL}^{-1}$ suspension under sonication. $10 \mu \mathrm{L}$ of homogeneous ink was coated onto a glassy carbon electrode (GCE) with $3 \mathrm{~mm}$ diameter. The electrochemical tests were carried out in a three-electrode system in $1.0 \mathrm{~mol} \mathrm{~L}^{-1} \mathrm{KOH}$ solution (sa- 
turated with $\mathrm{O}_{2}$ before use), with the modified electrode acting as the working electrode, the saturated calomel electrode (SCE) as the reference electrode, and a carbon rod as the counter electrode. The potentials measured versus SCE, were referenced to the reversible hydrogen electrode (RHE) by adding a value of $(0.241+0.059 \mathrm{pH}) \mathrm{V}$.

All of the potentials in the linear scan voltammograms (LSV) polarization plots were $i R$-compensated with respect to the ohmic resistance of the system, unless otherwise stated. The $i R$-correction was done based on the equation:

$E_{\text {corr }}=E_{\text {mea }}-i R$,

where $E_{\text {corr }}$ is the $i R$-corrected potential, $E_{\text {mea }}$ is the experimentally measured potential, and $R$ is the cell ohmic resistance. The overpotentials in this work were obtained by subtracting the theoretical value of the water oxidation:

$\eta=E(\mathrm{RHE})-1.23$.

Prior to the LSV tests, the modified working electrodes were subjected to continuous activation process by cyclic voltammetry $(\mathrm{CV})$ scanning until reproducible voltammograms appeared. The electrochemical impedance spectroscopy (EIS) information was obtained by the alternating current (AC) impedance spectroscopy in $1.0 \mathrm{~mol} \mathrm{~L}^{-1} \mathrm{KOH}$. The frequency ranged from $100 \mathrm{kHz}$ to $0.1 \mathrm{~Hz}$. A potential of $1.55 \mathrm{~V}$ was applied for the OER process and the amplitude was $5 \mathrm{mV}$. The measured impedance data were fitted with an equivalent circuit by the ZView software.

To explore the reaction mechanism and the Faradaic efficiency for the OER process, the rotating ring-disk electrode (RRDE) measurement was carried out. To explore the intermediate content of the possibly generated hydrogen peroxide, we fixed the ring potential at $1.50 \mathrm{~V}$, and did the tests in the $\mathrm{O}_{2}$-saturated $\mathrm{KOH}$ electrolyte. The disk and the ring polarization curves were recorded at $5 \mathrm{mV} \mathrm{s}^{-1}$ under $1600 \mathrm{rpm}$. The Faradaic efficiency was calculated as:

$\varepsilon=I_{\mathrm{r}} /\left(I_{\mathrm{d}} N\right)$,

in which $I_{\mathrm{d}}$ and $I_{\mathrm{r}}$ is the disk and ring current, respectively. The coefficient $N$ is the current collection efficiency of the RRDE equipment $(N=0.37)$. The $I_{\mathrm{d}}$ was fixed at a constant current of 180 and $470 \mu \mathrm{A}$, respectively to generate $\mathrm{O}_{2}$ and then reduced by sweeping across the surrounding Pt ring electrode which was set at $0.45 \mathrm{~V}$ for exhaustive oxygen reduction.

The accelerated stability tests were done by CV scanning between 1.20 and $1.60 \mathrm{~V}$ for 1000 cycles at $50 \mathrm{mV} \mathrm{s}^{-1}$. The obtained LSV plots before and after the multi-circle CV scanning were compared. The long-term operation stability of electrocatalysts was also evaluated by the chronopotentiometry method at a constant current density of $10 \mathrm{~mA} \mathrm{~cm}^{-2}$.

\section{Characterizations}

The morphologies of the catalysts were first observed with the field emission scanning electron microscope (FESEM, QUANTA FEG 250, FEI), and the transmission electron microscope (TEM, JEM-1400, JEOL Ltd., Japan). High-resolution TEM (HRTEM) and the dark field (DF)scanning transmission electron microscopy (STEM), and element mapping analysis were acquired from the FEI Talos F200s microscope equipped with energy-dispersive $\mathrm{X}$-ray spectroscopy (EDS) at $200 \mathrm{kV}$. The X-ray diffraction (XRD) results were obtained by an X-ray diffractometer (D8-Advance, Bruker) with the $\mathrm{Cu} \mathrm{Ka}$ radiation $(\lambda=1.5414 \AA)$. The X-ray photoelectron spectroscopy (XPS) measurements were performed on ESCALAB 250Xi instrument. The samples were also characterized by the Raman spectra (Renishaw Raman system model 1000 spectrometer with an excitation laser of $514 \mathrm{~nm}$ ). The surface areas of different electrocatalysts were measured by the $\mathrm{N}_{2}$ adsorption and desorption isotherms at $-196^{\circ} \mathrm{C}$ on a SSA-6000 (Builder) instrument.

\section{RESULTS AND DISCUSSION}

The Co-Ni-O $/$ / BG hybrid was fabricated by a facile chemical reduction method, followed by annealing treatment in $\mathrm{Ar}$ atmosphere at various temperatures. To be specific, the cobalt and nickel salts with different molar ratios were mixed with GO. After the metal ions were homogeneously adsorbed on the GO sheets, the mixture was subjected to reduction by $\mathrm{NaBH}_{4}$. Further heat treatment was also conducted to obtain the final product. The synthesis procedure and the electrocatalytic process for OER by the electrocatalyst-modified electrode are illustrated in Scheme 1.

The morphology of the as-prepared hybrid was evaluated by the FESEM, as shown in Fig. 1a. The SEM image of the $400^{\circ} \mathrm{C}$-annealed $\mathrm{Co}-\mathrm{Ni}-\mathrm{O}_{x} / \mathrm{BG}$ exhibits nanosheet morphology with a lateral size of several micrometers (similar to the unannealed samples in Fig. S1). Highmagnification SEM images demonstrate the existence of smaller nanosheets attached on the graphene sheets (Fig. 1b, c). The XRD pattern of the $400^{\circ} \mathrm{C}$-annealed Co$\mathrm{Ni}-\mathrm{O}_{x} / \mathrm{BG}$ sample is shown in Fig. 1d. The diffraction peak around $21^{\circ}$ corresponds to the diffraction of partially reduced graphene [32]. The peaks observed at $36.7^{\circ}$, $42.9^{\circ}$ and $62.2^{\circ}$ are symmetric and located between those of $\mathrm{CoO}$ (JCPDS card 44-1159) and $\mathrm{NiO}$ (JCPDS card 43- 


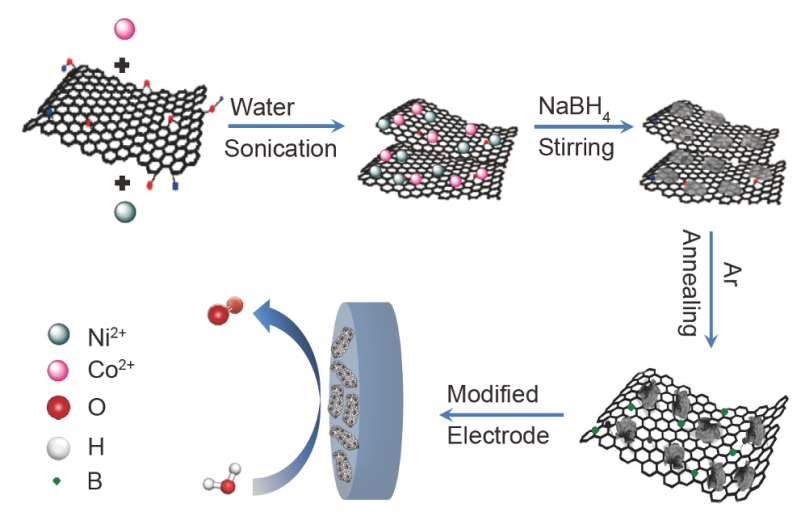

Scheme 1 Schematic illustration of the fabrication of the $\mathrm{Co}-\mathrm{Ni}-\mathrm{O}_{x} / \mathrm{BG}$ and the oxygen evolution process catalyzed by the $\mathrm{Co}-\mathrm{Ni}-\mathrm{O}_{x} / \mathrm{BG}$ modified electrode.

1004) [24]. It is consistent with the micro-adjustment of the lattice parameters, implying the formation of the cobalt nickel oxide alloy. The peak of graphene is much stronger than those of the bimetal oxide, indicating the weak XRD diffraction signals of the bimetal oxides, owing to the low annealing temperature. The XRD patterns of the composite with different $\mathrm{Co}: \mathrm{Ni}$ ratios are shown in
Fig. S2. The different nanosheet structures can be distinguished by the HRTEM images (Fig. 2). The EDS mapping results shown in Fig. $2 \mathrm{~d}-\mathrm{h}$ and Fig. S3 indicate that the $\mathrm{Co}, \mathrm{Ni}, \mathrm{O}, \mathrm{B}$, and $\mathrm{C}$ are well-distributed throughout the nanosheet matrix. The measured lattice spacing of $0.211 \mathrm{~nm}$ (Fig. 2c) is between those of $\mathrm{CoO}$ and $\mathrm{NiO}$. The lattice spacing data together with the XRD information imply the formation of cobalt nickel oxide alloy.

The Raman spectra further supports the formation of bimetallic oxide and graphene hybrid structure. In Fig. 3a, the broad Raman peak at ca. $520 \mathrm{~cm}^{-1}$ corresponds to the vibrations of cobalt oxide and nickel oxide $[33,34]$. The two main peaks at about 1351 and $1592 \mathrm{~cm}^{-1}$ are the $\mathrm{D}$ band peak (vibrations of $\mathrm{sp}^{3}$-bonded carbon atoms of the disordered graphene) and the $G$ band peak (in-plane vibration of $\mathrm{sp}^{2}$-bonded carbon atoms of the graphene), respectively [35].

The elemental composition and the valence state of the Co-Ni-O $/$ /BG hybrid were studied by XPS. The XPS survey spectrum (Fig. S4) confirms that the hybrid consists of $\mathrm{Co}, \mathrm{Ni}, \mathrm{O}, \mathrm{C}$, and $\mathrm{B}$ elements. The high-resolution core spectrum of Co 2 p in Fig. $3 b$ exhibits two main peaks
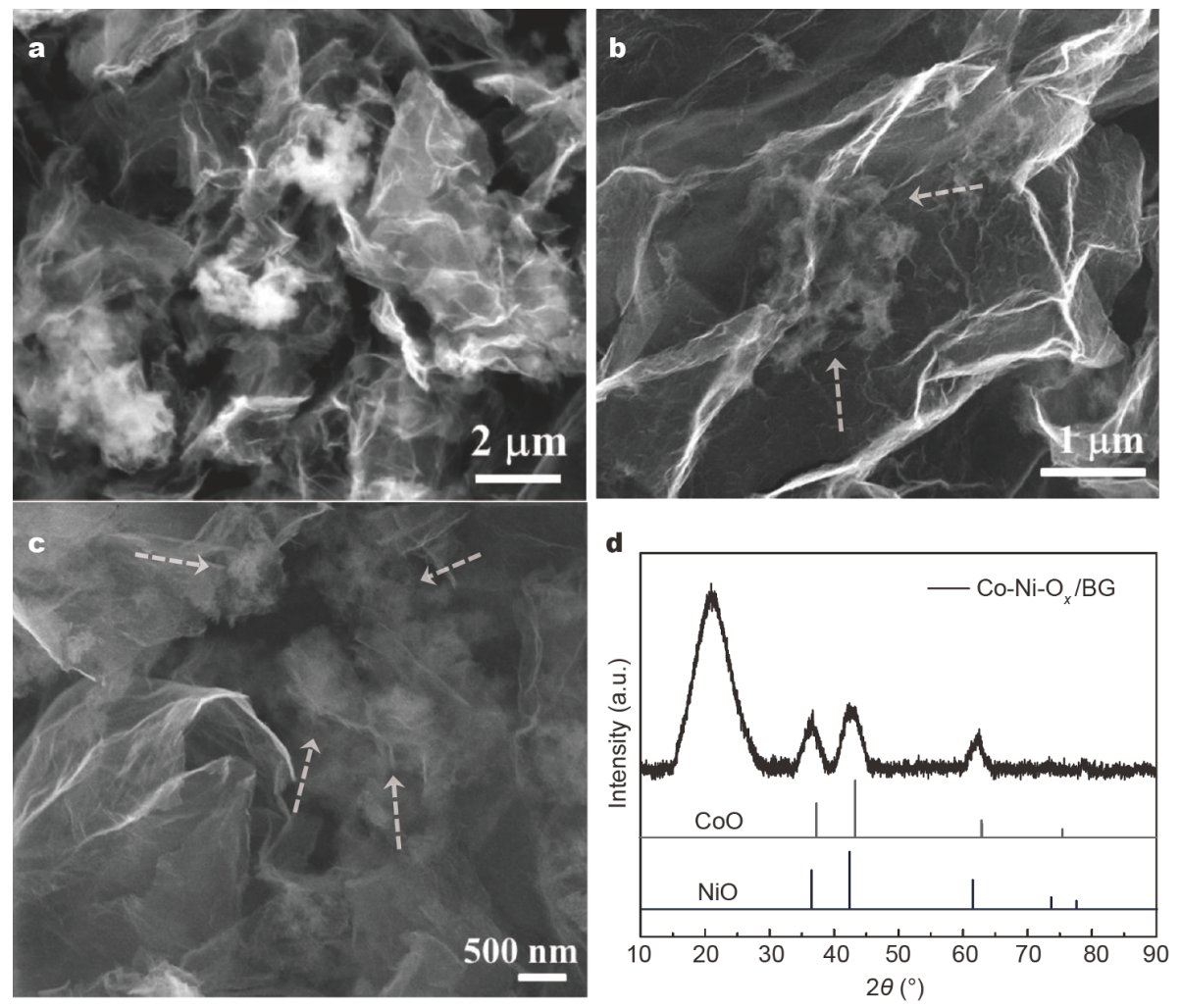

Figure $1(\mathrm{a}-\mathrm{c})$ SEM images of the $\mathrm{Co}-\mathrm{Ni}-\mathrm{O}_{x} / \mathrm{BG}$ hybrid under different magnifications (the arrows point to the more winkled nanosheet structures which are different from the graphene substrate). (d) XRD pattern of the Co-Ni- $\mathrm{O}_{x} / \mathrm{BG}$, below which the standard peaks of $\mathrm{CoO}$ and $\mathrm{NiO}$ are shown. 


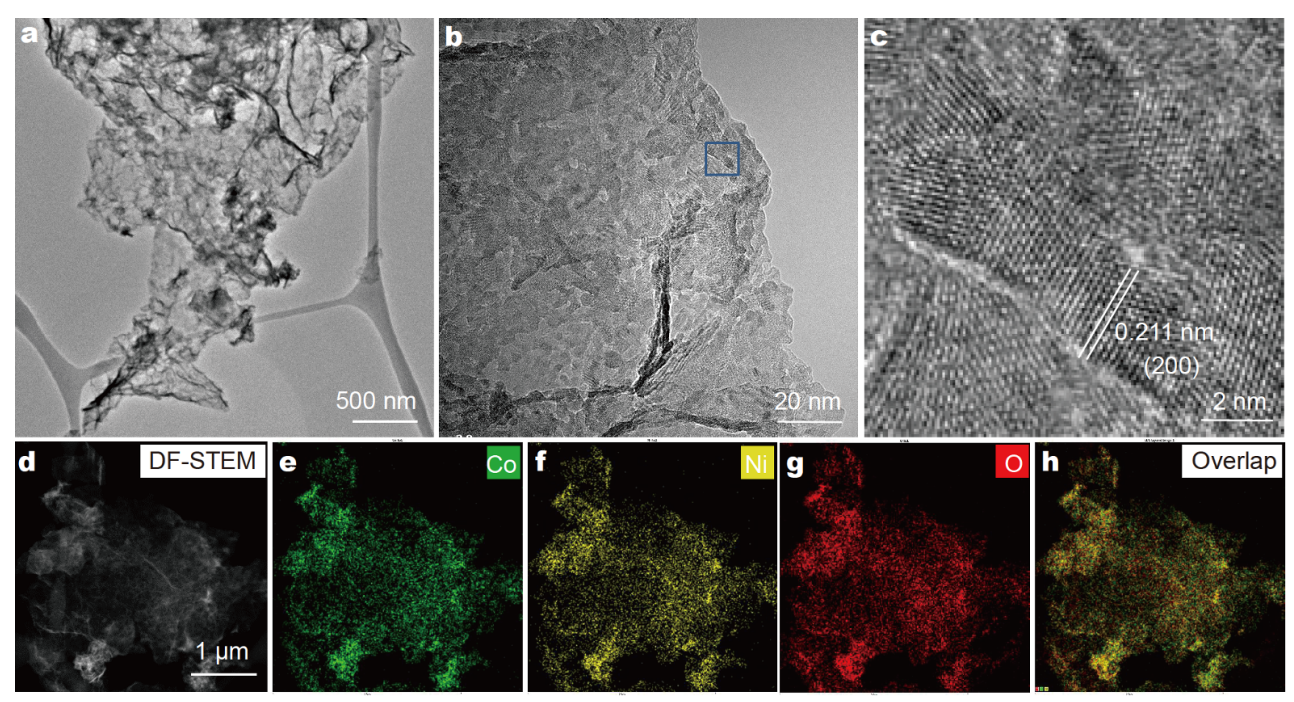

Figure 2 TEM (a, b) and HRTEM (c) images of the Co-Ni- $\mathrm{O}_{x} / \mathrm{BG},((\mathrm{c})$ is the amplified image of the blue square marked in (b)). The DF-STEM image (d) and the corresponding EDS elemental mappings of Co (e), Ni (f), O (g), and their overlap (h).
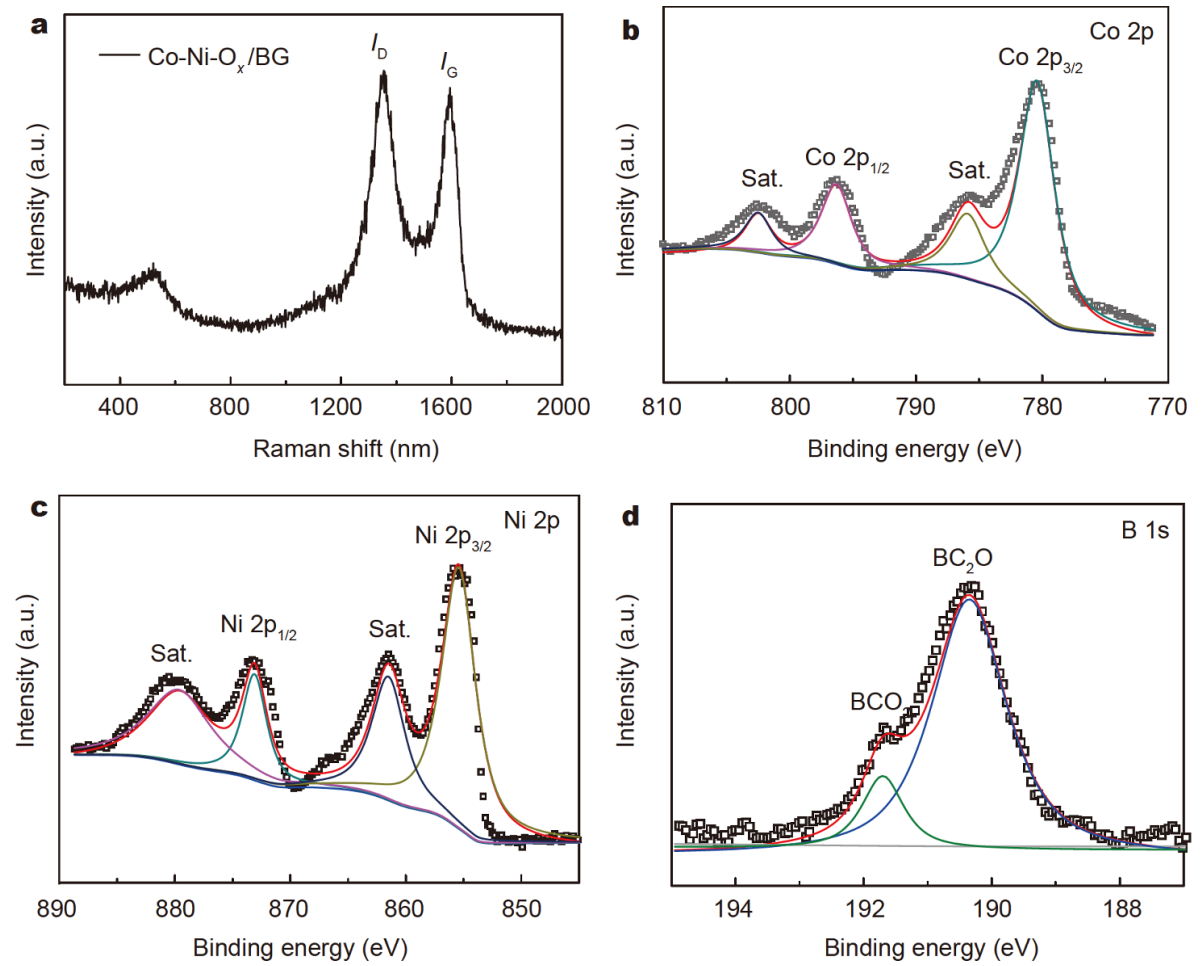

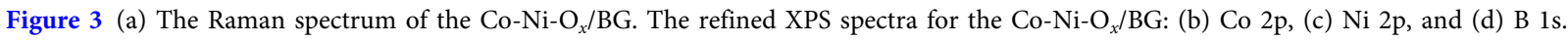

located at 780.4 and $796.3 \mathrm{eV}$ associated with two satellite peaks, which both belong to $\mathrm{Co}^{2+}$. The results are similar with the previously reported $\mathrm{CoO}$ XPS spectra $[36,37]$. Similarly, the $\mathrm{Ni}^{2+}$ is also clearly identified by the $\mathrm{Ni} 2 \mathrm{p}_{1 / 2}$ $(873.1 \mathrm{eV})$ and $\mathrm{Ni} 2 \mathrm{p}_{3 / 2}(855.4 \mathrm{eV})$ peaks with two satellite peaks (Fig. 3c) [37]. The high resolution spectrum of B 1s is overlapped by two peaks (Fig. 3d). The peak located at $190.3 \mathrm{eV}$ corresponds to $\mathrm{BC}_{2} \mathrm{O}$ groups, indicating $\mathrm{B}$ is doped within graphene in the epoxy form. The other peak located at $191.7 \mathrm{eV}$ is ascribed to the existence of small amount of boronic acid (borate) groups $\left(\mathrm{BCO}_{2}\right)[38,39]$. Combined with the previous characterizations, the an- 
nealed product is identified as BG-supported cobalt nickel oxide. We could also propose the formation process of the Co-Ni-O $\mathrm{O}_{x} / \mathrm{BG}$. As seen in Fig. S5, the unannealed product shows a broad peak at around $46^{\circ}$, indicating the formation of an amorphous bimetal borate structure [40]. During the annealing process, oxygen atoms from the borate and mildly reduced GO facilitate the formation of crystalline bimetal oxide with higher stability. Besides, some of the boron atoms are doped into the graphene skeleton, resulting in the formation of the Co- $\mathrm{Ni}-\mathrm{O}_{x} / \mathrm{BG}$, confirmed by the XPS results and EDS elemental mapping.

The electrocatalytic properties were evaluated by dropping the as-prepared catalysts onto the RDE. All electrochemical measurements in this study were carried out in a three-electrode system in $1.0 \mathrm{~mol} \mathrm{~L}^{-1} \mathrm{KOH}$ electrolyte. The LSV curves were obtained after $i R$ compensation (Fig. S6). Fig. S7 shows the LSV curves of the as-prepared mildly reduced GO-supported metal borate samples with different Co:Ni ratios (1:1, 2:1, 1:2, 1:0, 0:1) for OER. Note that all the bimetal borate samples exhibit much lower overpotentials than the mono-metal borate samples, indicating the favorable catalytic activity of the bimetal hybrids. These samples were then subjected to annealing treatment at $400^{\circ} \mathrm{C}$ in $\mathrm{Ar}$ atmosphere for $2 \mathrm{~h}$. The overpotentials and the Tafel slopes of the annealed products obviously reduce compared with those of the unannealed samples (Fig. 4a). Besides, the mildly reduced GO-supported bimetal borate (denoted as $\mathrm{Co}-\mathrm{Ni}-\mathrm{BO}_{x} /$ mrGO) precursor was also annealed at several temperatures, and the results were compared in Fig. S8. Electrochemical tests manifest that both the electrocatalyst composition and the annealing temperature have significant impacts on the activity of the graphene-supported bimetal oxide catalysts.

The overpotentials and the Tafel slopes obtained from various control experiments are depicted and compared in Fig. 4e, $\mathrm{f}$ (the abbreviations and their representative substances in Fig. 4e, $\mathrm{f}$ are stated in the Supplementary information). The Co-Ni- $\mathrm{O}_{x} / \mathrm{BG}$ shows the highest activity considering both the overpotential and Tafel slope. It is therefore selected for the detailed examination of the OER electrocatalytic performance. Fig. $4 \mathrm{~b}$ presents the LSV polarization curves of the $\mathrm{Co}-\mathrm{Ni}-\mathrm{O}_{x} / \mathrm{BG}$, the $400^{\circ} \mathrm{C}-$ annealed unsupported bimetal borides $\left(\mathrm{Co}-\mathrm{Ni}-\mathrm{O}_{x}\right)$ and the graphene, the commercial $\mathrm{RuO}_{2}$, and the bare GCE. The Co-Ni- $\mathrm{O}_{x} / \mathrm{BG}$ exhibits the lowest overpotential at $10 \mathrm{~mA} \mathrm{~cm}^{-2}(310 \mathrm{mV})$ compared with the bimetal oxides $(400 \mathrm{mV})$ and graphene $(520 \mathrm{mV})$, suggesting the coupling effect between the bimetal oxides and the graphene can improve the OER electrocatalytic activity of the hybrid. The Tafel slopes calculated from the LSV curves are also given in Fig. 4c. The Co-Ni-O $/$ / $/ \mathrm{BG}$ shows the smallest Tafel slope $\left(54.8 \mathrm{mV} \mathrm{dec}^{-1}\right)$, demonstrating its fast kinetics. This Tafel slope is close to the ideal value of $59.0 \mathrm{mV} \mathrm{dec}^{-1}$ (equivalent to $2.3 \mathrm{RT} / \mathrm{F}$ ), involving a oneelectron transfer process prior to the rate-limiting step $[41,42]$. The Co-Ni- $\mathrm{O}_{x} / \mathrm{BG}$ even outperforms the commercial $\mathrm{RuO}_{2}$ in the aspect of overpotential and Tafel slope $\left(330 \mathrm{mV}\right.$ and $62.7 \mathrm{mV} \mathrm{dec}^{-1}$ for the overpotential at $10 \mathrm{~mA} \mathrm{~cm}^{-2}$ and Tafel slope of commercial $\mathrm{RuO}_{2}$, respectively). To the best of our knowledge, this $\mathrm{Co}-\mathrm{Ni}-\mathrm{O}_{x} I$ BG exhibits better activity than many of the earthabundant transition metal-based OER catalysts (as seen in Table S1), even competitive with noble-metal-based ones [43].

The EIS measurements of the Co-Ni- $\mathrm{O}_{x} / \mathrm{BG}, \mathrm{Co}-\mathrm{Ni}-\mathrm{O}_{x}$, graphene, and the commercial $\mathrm{RuO}_{2}$ were conducted in $\mathrm{KOH}$ solution (Fig. 4d). The EIS curves can be fitted with an equivalent circuit composed of a series of resistance ( $R_{\mathrm{s}}$, mainly the solution resistance, and $R_{\mathrm{ct}}$, the charge transfer resistance) and a constant phase element. The $R_{\mathrm{s}}$ value and the $R_{\mathrm{ct}}$ value are closely related to the kinetics of the electrocatalytic process. These data indicate that the Co-Ni- $\mathrm{O}_{x} / \mathrm{BG}$ has smaller charge transfer resistance than Co-Ni- ${ }_{x}$, graphene, and $\mathrm{RuO}_{2}$, indicating a faster charge transfer process in the Co-Ni- $\mathrm{O}_{x} / \mathrm{BG}$ electrocatalysts [44]. This is in accordance with the low overpotential and small Tafel slope of the Co-Ni- $\mathrm{O}_{x} / \mathrm{BG}$.

In order to further ascertain the catalytic mechanism of the electrocatalysts, the RRDE method was also used to oxidize the possible hydrogen peroxide intermediates generated at the electrocatalyst surface during the water oxidation process. The Pt ring electrode was set at $1.50 \mathrm{~V}$ $v s$. RHE. Fig. 5a shows fairly low ring current (about three orders of magnitude lower than that of the disk current), demonstrating the negligible $\mathrm{H}_{2} \mathrm{O}_{2}$ generation, which corresponds to a desired four-electron transfer pathway of the $\mathrm{Co}-\mathrm{Ni}-\mathrm{O}_{x} / \mathrm{BG}$ for water oxidation $[40,45]$. Furthermore, the Faradaic efficiency tests were also conducted to confirm this result. The ring electrode was applied with a potential of $0.45 \mathrm{~V}$ to reduce the in-situ generated $\mathrm{O}_{2}$ in the disk electrode, giving a persistent OER (disk electrode) $\rightarrow$ ORR (ring electrode) process. Fig. 5b exhibits that the collected ring current is ca. 66.5 and $171.4 \mu \mathrm{A}$, with the applied disk current at 180 and $470 \mu \mathrm{A}$, corresponding to the calculated Faradaic efficiency of $99.7 \%$ and $98.6 \%$, respectively.

The accelerated degradation test was carried out by comparing the LSV polarization curves before and after 

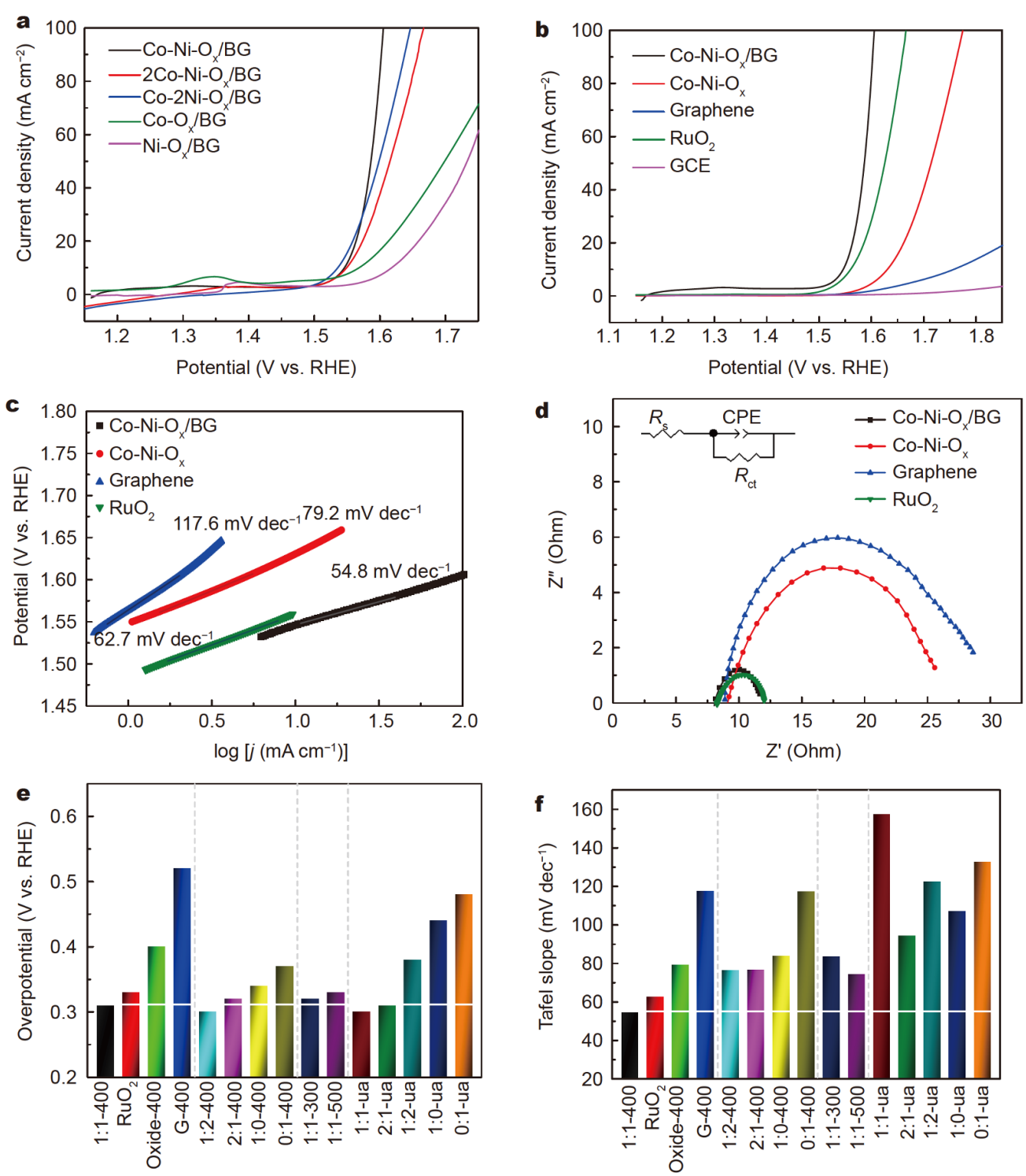

Figure 4 (a) The LSV curves of the annealed BG coupled bimetal oxides with different Co:Ni ratios in $1.0 \mathrm{~mol} \mathrm{~L}^{-1} \mathrm{KOH}$ solution. (b, c) The LSV

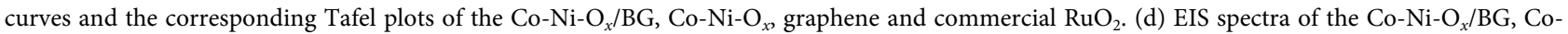
$\mathrm{Ni}-\mathrm{O}_{x}$, graphene, and commercial $\mathrm{RuO}_{2}$ samples (inset: the corresponding equivalent circuit). (e, f) Bar graphs for easy comparison of the overpotentials of various catalysts $\left(10 \mathrm{~mA} \mathrm{~cm}^{-2}\right)$, and the Tafel slopes obtained from the OER polarization curves.

multiple CV cycling to evaluate the durability of the catalyst in the OER process. As seen in Fig. 6a, after 1000 cycles, the LSV curve of Co-Ni- $\mathrm{O}_{x} / \mathrm{BG}$ only shifts marginally compared with the initial one. This small change in the potential demonstrates good cycling performance of the Co-Ni- $\mathrm{O}_{x} / \mathrm{BG}$ catalysts. We also examined the morphology change of the catalyst before and after the above-mentioned durability test. The structure maintains well in the graphene-supported bimetal oxides after the test, which can be discerned from the SEM images
(Fig. S9), demonstrating that after long-term operation, the high OER activity of the catalyst can be well-maintained. The Co-Ni-O $\mathrm{O}_{x} / \mathrm{BG}$ shows a potential change of only $17 \mathrm{mV}$ during $12 \mathrm{~h}$ constant-current $\left(10 \mathrm{~mA} \mathrm{~cm}^{-2}\right)$ measurements, further confirming its high stability in the OER process (Fig. $6 \mathrm{~b}$ ).

The electrochemical surface area (ECSA) is frequently served as an approximate presentation for the surface roughness of electrocatalyst within one order-of-magnitude accuracy [46]. We measured the double layer capa- 

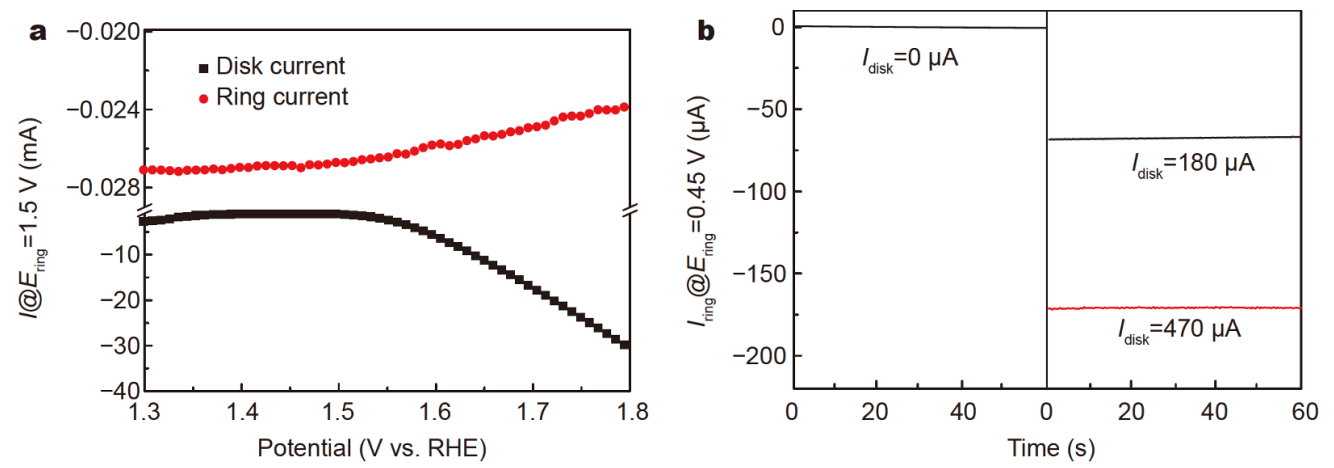

Figure 5 (a) The disk and ring current of $\mathrm{Co}-\mathrm{Ni}_{-} \mathrm{O}_{x} / \mathrm{BG}$ electrocatalyst on the RRDE equipment $(1600 \mathrm{rpm})$ with the ring potential applied at $1.50 \mathrm{~V}$ in $1.0 \mathrm{~mol} \mathrm{~L}^{-1} \mathrm{KOH}$ solution. (b) Ring currents of the $\mathrm{Co}-\mathrm{Ni}-\mathrm{O}_{x} / \mathrm{BG}$ on the RRDE equipment $(1600 \mathrm{rpm}$ ) with the ring potential applied at $0.45 \mathrm{~V}$ at different disk currents $(180$ and $470 \mu \mathrm{A})$.
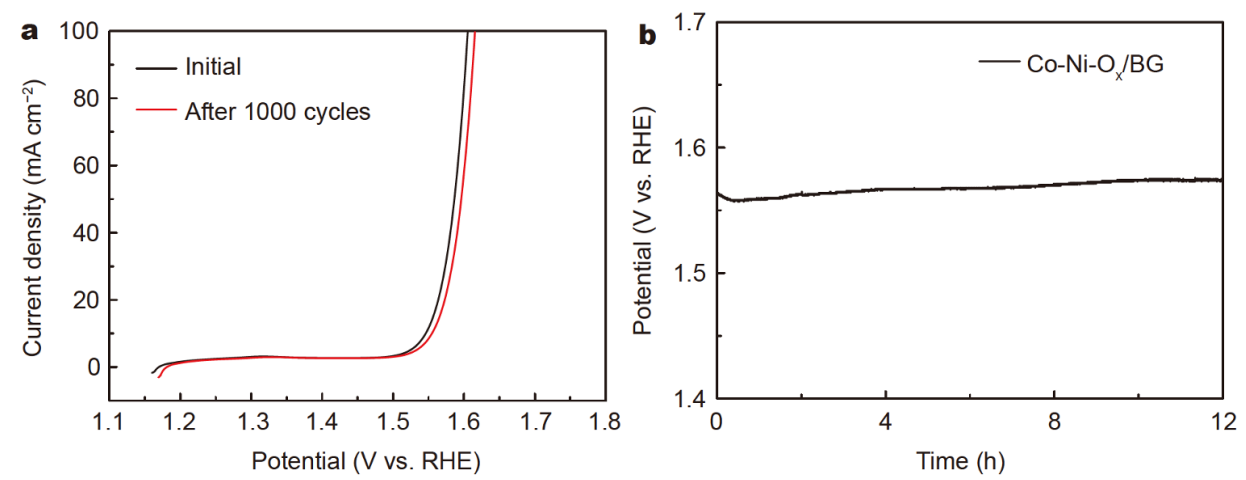

Figure 6 (a) LSV curves of the Co-Ni-O $\mathrm{O}_{x} / \mathrm{BG}$ electrocatalyst before and after $1000 \mathrm{CV}$ cycles. (b) The chronopotentiometric curve ( $v s$. RHE) at $10 \mathrm{~mA} \mathrm{~cm}^{-2}$ for the $\mathrm{Co}-\mathrm{Ni}-\mathrm{O}_{x} / \mathrm{BG}$ in $1.0 \mathrm{~mol} \mathrm{~L}^{-1} \mathrm{KOH}$ electrolyte.

citance at the solid-liquid interface to estimate the electrochemical surface areas. The double layer capacitance values of the annealed graphene-supported bimetal oxide samples with different Co:Ni ratios are close to each other (Fig. S10). The Brunauer-Emmett-Teller (BET) measurements were also carried out, as shown in Fig. S11. The results manifest that the BET surface areas of the graphene-supported bimetal oxide samples with different Co:Ni ratios have little difference (Fig. S11). This indicates that the activity advantage of the $\mathrm{Co}-\mathrm{Ni}-\mathrm{O}_{x} / \mathrm{BG}$ has little relationship with the specific surface area or the ECSA. The higher activity of the Co-Ni- $\mathrm{O}_{x} / \mathrm{BG}$ can be attributed to the appropriate $\mathrm{Co}: \mathrm{Ni}$ ratio, which induces the enhancement in the charge transfer ability. The activity improvement arising upon annealing treatment primarily depends on the enhanced conductivity induced by the reduction of GO, as manifested by the EIS results shown in Fig. S12. By reasonably designing and carrying out a series of control experiments, this study offers effective ways for improving the OER performance of the electrocatalyst. First, the elementary composition of the bimetal oxides should be modulated in order to change the microenvironment of the surface electron of the transition metal. Second, a post-annealing process is necessary to regulate the crystalline structures of the catalysts. Lastly, taking advantage of the strong coupling effect between the active electrocatalyst and the conductive support, the synergetic effects between the coupled materials may lead to distinct improvement on the electrocatalytic performance.

\section{CONCLUSIONS}

In summary, a novel $\mathrm{Co}-\mathrm{Ni}-\mathrm{O}_{x} / \mathrm{BG}$ nanohybrid was fabricated via a facile co-reduction approach followed by an annealing process, providing a scalable and economical method for the preparation of graphene-supported bimetal oxide catalysts. The properly annealed sample with an optimal composition $\left(\mathrm{Co}-\mathrm{Ni}-\mathrm{O}_{x} / \mathrm{BG}\right)$ exhibits a high electrocatalytic activity for the OER in alkaline electrolyte. High stability of the catalyst is also testified by the long- 
term operation process and the accelerated degradation test. The high OER electrocatalytic performance of the $\mathrm{Co}-\mathrm{Ni}-\mathrm{O}_{x} / \mathrm{BG}$ can be attributed to the unique structure of the hybrid which is favorable for the exposure of active sites, and the strong synergistic coupling effects between the bimetal oxides and graphene. This work offers several effective ways for improving the OER performance of the electrocatalyst, such as modulating the elemental ratio of the bimetal oxides, appropriate annealing treatment, and capitalizing on the strong coupling effect. This study can promote the development of non-noble metal hybrid materials for highly active OER electrocatalysts in the electrochemical water splitting process.

\section{Received 6 February 2020; accepted 27 February 2020; published online 8 April 2020}

1 Chow J, Kopp RJ, Portney PR. Energy resources and global development. Science, 2003, 302: 1528-1531

2 Shen FC, Sun SN, Xin ZF, et al. Hierarchically phosphorus doped bimetallic nitrides arrays with unique interfaces for efficient water splitting. Appl Catal B-Environ, 2019, 243: 470-480

3 Ma TY, Ran J, Dai S, et al. Phosphorus-doped graphitic carbon nitrides grown in situ on carbon-fiber paper: flexible and reversible oxygen electrodes. Angew Chem Int Ed, 2015, 54: 4646-4650

4 Yi JD, Liu TT, Huang YB, et al. Solid-state synthesis of $\mathrm{MoS}_{2}$ nanorod from molybdenum-organic framework for efficient hydrogen evolution reaction. Sci China Mater, 2019, 62: 965-972

5 Zou X, Zhang Y. Noble metal-free hydrogen evolution catalysts for water splitting. Chem Soc Rev, 2015, 44: 5148-5180

6 Man IC, Su H-, Calle-Vallejo F, et al. Universality in oxygen evolution electrocatalysis on oxide surfaces. ChemCatChem, 2011, 3: $1159-1165$

7 McCrory CCL, Jung S, Peters JC, et al. Benchmarking heterogeneous electrocatalysts for the oxygen evolution reaction. J Am Chem Soc, 2013, 135: 16977-16987

8 McCrory CCL, Jung S, Ferrer IM, et al. Benchmarking hydrogen evolving reaction and oxygen evolving reaction electrocatalysts for solar water splitting devices. J Am Chem Soc, 2015, 137: 4347-4357

9 Lee Y, Suntivich J, May KJ, et al. Synthesis and activities of rutile $\mathrm{IrO}_{2}$ and $\mathrm{RuO}_{2}$ nanoparticles for oxygen evolution in acid and alkaline solutions. J Phys Chem Lett, 2012, 3: 399-404

10 Oh SK, Kim HW, Kwon YK, et al. Porous Co-P foam as an efficient bifunctional electrocatalyst for hydrogen and oxygen evolution reactions. J Mater Chem A, 2016, 4: 18272-18277

11 Qiao X, Jin J, Fan H, et al. In situ growth of cobalt sulfide hollow nanospheres embedded in nitrogen and sulfur co-doped graphene nanoholes as a highly active electrocatalyst for oxygen reduction and evolution. J Mater Chem A, 2017, 5: 12354-12360

12 Suen NT, Hung SF, Quan Q, et al. Electrocatalysis for the oxygen evolution reaction: recent development and future perspectives. Chem Soc Rev, 2017, 46: 337-365

13 Han L, Dong S, Wang E. Transition-metal (Co, Ni, and Fe)-based electrocatalysts for the water oxidation reaction. Adv Mater, 2016, 28: 9266-9291

14 Jin $\mathrm{Y}$, Wang $\mathrm{H}, \mathrm{Li} \mathrm{J}$, et al. Porous $\mathrm{MoO}_{2}$ nanosheets as non-noble bifunctional electrocatalysts for overall water splitting. Adv Mater, 2016, 28: 3785-3790
15 Feng JX, Xu H, Dong YT, et al. FeOOH/Co/FeOOH hybrid nanotube arrays as high-performance electrocatalysts for the oxygen evolution reaction. Angew Chem Int Ed, 2016, 55: 3694-3698

16 An L, Feng J, Zhang Y, et al. Epitaxial heterogeneous interfaces on $\mathrm{N}-\mathrm{NiMoO}_{4} / \mathrm{NiS}_{2}$ nanowires/nanosheets to boost hydrogen and oxygen production for overall water splitting. Adv Funct Mater, 2019, 29: 1805298

17 Dong B, Zhao X, Han GQ, et al. Two-step synthesis of binary NiFe sulfides supported on nickel foam as highly efficient electrocatalysts for the oxygen evolution reaction. J Mater Chem A, 2016, 4: $13499-13508$

18 Ganesan P, Prabu M, Sanetuntikul J, et al. Cobalt sulfide nanoparticles grown on nitrogen and sulfur codoped graphene oxide: an efficient electrocatalyst for oxygen reduction and evolution reactions. ACS Catal, 2015, 5: 3625-3637

19 Jiang Y, Chen C, Ni P, et al. Efficient water splitting catalyzed by cobalt phosphide nanobead-chain like nanoarrays supported on three dimensional nickel foam. Chin J Anal Chem, 2018, 46: 550555

20 Jiang Y, Lu Y, Lin J, et al. A hierarchical MoP nanoflake array supported on $\mathrm{Ni}$ foam: a bifunctional electrocatalyst for overall water splitting. Small Methods, 2018, 2: 1700369

21 Ma X, Wen J, Zhang S, et al. Crystal $\mathrm{Co}_{x} \mathrm{~B}(x=1-3)$ synthesized by a ball-milling method as high-performance electrocatalysts for the oxygen evolution reaction. ACS Sustain Chem Eng, 2017, 5: 10266-10274

22 Masa J, Weide P, Peeters D, et al. Amorphous cobalt boride $\left(\mathrm{Co}_{2} \mathrm{~B}\right)$ as a highly efficient nonprecious catalyst for electrochemical water splitting: oxygen and hydrogen evolution. Adv Energy Mater, 2016, 6: 1502313

23 Feng T, Zhao XR, Dong CK, et al. Boosting reversible oxygen electrocatalysis with enhanced interfacial pyridinic-N-Co bonding in cobalt oxide/mesoporous $\mathrm{N}$-doped graphene hybrids. Nanoscale, 2018, 10: 22140-22147

24 Tong Y, Chen P, Zhou T, et al. A bifunctional hybrid electrocatalyst for oxygen reduction and evolution: cobalt oxide nanoparticles strongly coupled to B,N-decorated graphene. Angew Chem Int Ed, 2017, 56: 7121-7125

25 Xiao C, Li Y, Lu X, et al. Bifunctional porous $\mathrm{NiFe} / \mathrm{NiCo}_{2} \mathrm{O}_{4} / \mathrm{Ni}$ foam electrodes with triple hierarchy and double synergies for efficient whole cell water splitting. Adv Funct Mater, 2016, 26: 3515-3523

26 Wang C, Jiang J, Ding T, et al. Monodisperse ternary NiCoP nanostructures as a bifunctional electrocatalyst for both hydrogen and oxygen evolution reactions with excellent performance. Adv Mater Interfaces, 2016, 3: 1500454

27 He T, Nsanzimana JMV, Qi R, et al. Synthesis of amorphous boride nanosheets by the chemical reduction of Prussian blue analogs for efficient water electrolysis. J Mater Chem A, 2018, 6: 23289-23294

28 Gupta S, Patel N, Fernandes R, et al. Co-Mo-B nanoparticles as a non-precious and efficient bifunctional electrocatalyst for hydrogen and oxygen evolution. Electrochim Acta, 2017, 232: 64-71

29 Jia X, Zhao $\mathrm{Y}$, Chen $\mathrm{G}$, et al. $\mathrm{Ni}_{3} \mathrm{FeN}$ nanoparticles derived from ultrathin NiFe-layered double hydroxide nanosheets: an efficient overall water splitting electrocatalyst. Adv Energy Mater, 2016, 6: 1502585

30 Zhang J, Li X, Liu Y, et al. Bi-metallic boride electrocatalysts with enhanced activity for the oxygen evolution reaction. Nanoscale, 2018, 10: 11997-12002 
31 Yang $\mathrm{H}$, Wang $\mathrm{C}$, Zhang $\mathrm{Y}$, et al. Green synthesis of NiFe LDH/Ni foam at room temperature for highly efficient electrocatalytic oxygen evolution reaction. Sci China Mater, 2019, 62: 681-689

32 Shin H-, Kim KK, Benayad A, et al. Efficient reduction of graphite oxide by sodium borohydride and its effect on electrical conductance. Adv Funct Mater, 2009, 19: 1987-1992

33 Rivas-Murias B, Salgueiriño V. Thermodynamic $\mathrm{CoO}-\mathrm{Co}_{3} \mathrm{O}_{4}$ crossover using Raman spectroscopy in magnetic octahedronshaped nanocrystals. J Raman Spectrosc, 2017, 48: 837-841

34 Singh R, Kumar S, Bedi RK, et al. Optimization of $\mathrm{Ni}^{2+} / \mathrm{Ni}^{3+}$ ratio in reduced graphene oxide/nickel oxide nanohybrids for platinum free dye sensitized solar cells. J Phys Chem Solids, 2018, 123: 191197

35 Jiang Y, Lu Y, Lv X, et al. Enhanced catalytic performance of Ptfree iron phthalocyanine by graphene support for efficient oxygen reduction reaction. ACS Catal, 2013, 3: 1263-1271

36 Dedryvère R, Laruelle S, Grugeon S, et al. Contribution of X-ray photoelectron spectroscopy to the study of the electrochemical reactivity of $\mathrm{CoO}$ toward lithium. Chem Mater, 2004, 16: 10561061

37 Liu X, Liu W, Ko M, et al. Metal (Ni,Co)-metal oxides/graphene nanocomposites as multifunctional electrocatalysts. Adv Funct Mater, 2015, 25: 5799-5808

38 Zhang Y, Zhao J, Sun H, et al. B, N, S, Cl doped graphene quantum dots and their effects on gas-sensing properties of $\mathrm{Ag}-\mathrm{LaFeO}_{3}$. Sens Actuat B-Chem, 2018, 266: 364-374

39 Sheng ZH, Gao HL, Bao WJ, et al. Synthesis of boron doped graphene for oxygen reduction reaction in fuel cells. J Mater Chem, 2012, 22: 390-395

40 Cao X, Cui L, Wang X, et al. Nickel-borate/reduced graphene oxide nanohybrid: a robust and efficient electrocatalyst for oxygen evolution reaction in alkaline and near neutral media. ChemCatChem, 2018, 10: 2826-2832

41 Surendranath Y, Kanan MW, Nocera DG. Mechanistic studies of the oxygen evolution reaction by a cobalt-phosphate catalyst at neutral pH. J Am Chem Soc, 2010, 132: 16501-16509

42 Li D, Baydoun $\mathrm{H}$, Verani CN, et al. Efficient water oxidation using CoMnP nanoparticles. J Am Chem Soc, 2016, 138: 4006-4009

43 Anantharaj S, Ede SR, Sakthikumar K, et al. Recent trends and perspectives in electrochemical water splitting with an emphasis on sulfide, selenide, and phosphide catalysts of $\mathrm{Fe}, \mathrm{Co}$, and $\mathrm{Ni}$ : a review. ACS Catal, 2016, 6: 8069-8097

44 Jiang Y, Fang Y, Chen C, et al. Amorphous cobalt boride nanosheets directly grown on nickel foam: controllable alternately dipping deposition for efficient oxygen evolution. ChemElectroChem, 2019, 6: 3684-3689

45 Chen P, Xu K, Zhou T, et al. Strong-coupled cobalt borate nanosheets/graphene hybrid as electrocatalyst for water oxidation under both alkaline and neutral conditions. Angew Chem Int Ed, 2016, 55: 2488-2492

46 Trasatti S, Petrii OA. Real surface area measurements in electrochemistry. J Electroanal Chem, 1992, 327: 353-376

Acknowledgements The authors acknowledge the financial supports from the National Natural Science Foundation of China (21902062 and 21705056), the Natural Science Foundation of Shandong Province (ZR2019YQ10 and ZR2018PB009), the Young Taishan Scholars Program (tsqn201812080), and the Open Funds of the State Key Laboratory of Electroanalytical Chemistry (SKLEAC201901).
Author contributions Jiang $\mathrm{Y}$ designed and engineered the samples; Dong K operated the experiments with the help from Jiang Y; Jiang Y analyzed the data and wrote the paper with the support from $\mathrm{Lu} \mathrm{Y}$; Chen $\mathrm{B}$ together with Liu J helped to revise and polish the paper; Song $\mathrm{Z}$ and Niu L helped to conduct some characterizations such as XPS and Raman; all authors contributed to the general discussion.

Conflict of interest The authors declare no conflict of interest.

Supplementary information Supporting data are available in the online version of the paper.

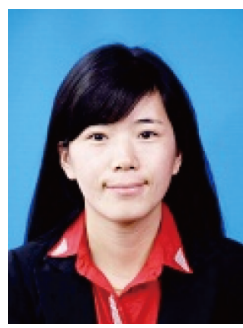

Yuanyuan Jiang received her bachelor's degree from Jilin University in 2009. She then obtained the $\mathrm{PhD}$ degree from Changchun Institute of Applied Chemistry, Chinese Academy of Sciences in 2015. Afterwards she worked as a postdoctoral fellow in Nanyang Technological University. In 2017, she joined the School of Materials Science and Engineering, University of Jinan. Her scientific interests focus on the development of nano-structure materials for energy conversion and storage and electroanalysisrelevant applications.

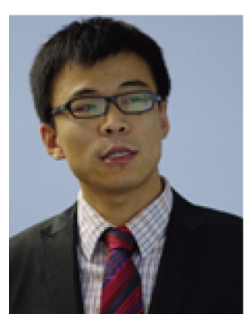

Yizhong Lu received his $\mathrm{PhD}$ from Changchun Institute of Applied Chemistry, Chinese Academy of Sciences (2015). He then worked as a research fellow at Nanyang Technological University \& Cambridge Center for Advanced Research in Energy Efficiency in Singapore. Currently, he is a full professor in the School of Materials Science and Engineering, University of Jinan. His research interests focus on the sizecontrolled synthesis, characterization, and sizedependent property study of metal nanocusters, nanobiosensing, and electrochemisty.

\section{䂽掺杂石墨烯耦合双金属氧化物作为高效氧气析 出电催化剂}

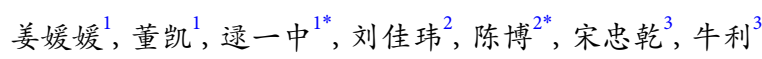

摘要 开发高效价廉的氧气析出反应电催化剂对于制备多种可再 生能量转化和存储器件至关重要. 本文中, 我们设计合成了一系列 硼掺杂石墨烯负载的钴镍双金属氧化物, 并研究了其氧气析出电 催化性能. 研究结果表明适当温度下退火后的 $\mathrm{Co}-\mathrm{Ni}-\mathrm{O}_{x} / \mathrm{BG}(\mathrm{Co} /$ $\mathrm{Ni}$ 比为 $1: 1$ )在碱性条件下表现出非常高的氧气析出电催化性能. 在 电流密度为 $10 \mathrm{~mA} \mathrm{~cm}^{-2}$ 时, 该电催化剂对氧气析出反应的过电位 仅为 $310 \mathrm{mV}$, 优于绝大多数已报道的基于单金属氧化物的催化剂, 甚至可与商业 $\mathrm{RuO}_{2}$ 电催化剂的性能相媲美. 该双金属氧化物复合 材料中, 电荷分布的微调控及协同耦合效应都对该材料的电催化 性能起到了促进作用. 另外, 本文还提出了几种可有效提高氧化物 材料氧气析出电催化活性的方法. 